\title{
Quantifying Semantics Using Statistical Tools: An Empirical Research in Colour Compounds in Modern Greek
}

\author{
Dimitra Serakioti, PhD \\ National and Kapodistrian University of Athens, Greece
}

Doi:10.19044/esj.2020.v16n23p185 URL:http://dx.doi.org/10.19044/esj.2020.v16n23p185

\begin{abstract}
The present paper attempts an empirical investigation of the semantic impact of colour compounds in Modern Greek interpretation. The study adopted the framework put forward by Berlin and Kay (1969), statistical tools were used for data analysis and Venn diagrams depicted the relationship between the compounding elements. Taking into consideration that the research literature supports the view that colour compounds may be considered as coordinates, and despite the intuition, that native speakers are likely to consider the second constituent as basic one according to the Righthand Head Rule that applies for Greek, the results of our experiments negate our two hypotheses. Specifically, respondents' perception regarding colour compounds tends to acknowledge the first constituent as strongest. This might well be attributed to the gradual left-to-right speech processing, as observed at the sentence level. Moreover, the alternate order of the constituents does not lead to different intuitions.
\end{abstract}

Keywords: Quantitative semantics, morphology, Right-hand head rule, Berlin \& Kay's experiment, Venn diagrams

\section{Introduction}

Over the last decades, morphological head, that is the element that percolates to the compound its grammatical category, its morphosyntactic and semantic features, has attracted increasing interest among researchers (see Selkirk, 1982; DiSciullo \& Williams, 1987; Booij, 2007; Lieber, 2009; Scalise \& Fábregas, 2010; Ralli, 2013; Bauer, 2017). The impact of compound head and semantic opacity in the interpretation has been a thought-provoking field, among others, by Fabb (2001), Booij (2007), Lieber (2009, 2016), Bauer (2008, 2017), Bourque (2014), Gagné \& Spalding (2015), Bell \& Schäfer (2016) and Jackendoff (2016). The fact that many languages appear to have the head rightmost of the compounds led Williams (1981) to formulate his 
Right-hand Head Rule. In Greek compounds, as well as in those of English, Russian, Turkish and Dutch, this rule applies as long as the head is on the right (see Manouilidou et al., 2012: 236; Ralli, 2013: 99).

Regarding the role of head in compounding, several experiments have been conducted mainly in the field of psycholinguistics, emphasizing the close relationship of the compound's head with the degree of its transparency, as for French and Polish (Jarema et al., 1999), English (Libben, 1998; Juhasz, 2007; Frisson et al., 2008), Finnish (Pollatsek \& Hyönä, 2005), German (Isel et al., 2003), Dutch (Sandra, 1990) and Italian (Marelli \& Luzzati, 2012). For Modern Greek, the only empirical study is that of Manouilidou et al. (2012), examining the interpretation of coordinative compounds, pointing to the contribution of both components to the representation of the whole compound, something Jarema \& al. (1999) also support. The structure of colour compounds has been investigated, among others, by Ten Hacken (2000), Wälchli (2005), Bauer (2008, 2017), Manolessou \& Tsolakidis (2009), Ralli (2009, 2013), Arcodia et al. (2010), Serakioti \& Markopoulos (2013), Jackendoff (2016), Serakioti (2019). In general, these types of compounds are considered either as coordinative, without either of the two components being the basis of the colour compound, or as compounds with a dependent relationship, with the whole compound being a type of the second component. In the present study, the semantic relation between the two components through the Munsell spectrum, as well as the Right-hand head rule hypothesis, will be investigated in colour compounds using statistical tools to semantic interpretation. The main purpose of the study is: a) to empirically test whether speakers split their attention between the two constituents or they are likely to concentrate on the first or the second colour, based either on the colour palette, as well as to study the semantic processes that are implemented in compounding; b) to explore whether the alternation of the constituents leads speakers to a different intuition.

Also, in the context of semantic relationships between compound and its components, an issue of particular interest is how to represent them with Venn diagrams. These types of diagrams, in addition to being easily understood by the user, without any ambiguities, provide the greatest possible clarity in the display of the sets (see, among others, Hertzum \& Frøkjær, 1996; Nakatsu, 2010; Sato \& Mineshima, 2015). A kind of representation of semantic relationships with Venn diagrams has been attempted by Wälchli (2005), Bauer (2008) and Bourque (2014), but without a clear and complete model of their compounding representation. In the present study, a mathematical model is proposed using Venn diagrams, which is not only limited to show the semantic relationship in the components of colour compounds but finds application in various compound categories. 
The study of semantic relations between the two components through the Munsell spectrum, as well as the investigation of the hypothesis of the Right-hand head rule with absolute mathematical precision, is innovation and contribution to the international research literature. Also, Venn diagrams provide the greatest possible accuracy and clarity in the depiction of the semantic relationships of the components of the compound. ${ }^{21}$

\section{Methodology}

\subsection{Materials and research procedure}

Berlin \& Kay (1969), based on experiments conducted on native speakers of twenty different languages, argue that there is a universal index of exactly eleven basic colours. Particularly, all languages appeared to have terms for black and white. The other colour terms are red, green, yellow, blue, brown, purple, pink, orange and gray (Berlin \& Kay, 1969: 2-4).

The present study examined the colour spectrum of Berlin \& Kay (1969). This spectrum contains 330 chromatic cells, of which 320 represent 40 different hues. Each of these hues is further divided into 8 different levels of brightness (Munsell value). The other cells represent seven levels of gray. For this study, two experiments were designed using the second stage of data collection, in which participants were asked to find the typical version of basic colours (Berlin \& Kay, 1969: 5). ${ }^{22}$

In experiment 1, the Munsell spectrum was given to the research participants and asked to identify separately the characteristic version of the following colours: kokino (red), prasino (green), kitrino (yellow), portokali (orange), and galazio ${ }^{23}$ (light blue). These colour terms were chosen to be used to create compound words in experiment 2 . The purpose of the first experiment was to create a baseline for interpreting the data in the next experiment (experiment 2).

In experiment 2, in addition to the Berlin and Kay's experiments, the volunteers were asked to find the characteristic version in four pairs of basic colours, such as yellow-green and green-yellow, through the Munsell spectrum. This experiment aimed to test whether the speakers' perception is between the two components or tends more to the first or the second part,

\footnotetext{
${ }^{1}$ It is the first time that Venn diagrams are systematically applied to depict semantic relations proposing a universal compound representation. The study of Serakioti \& Markopoulos (2013) was a first approach to the interpretation of colour compounds, while experiments in the present paper confirm the main findings using expanded quantitative methods.

${ }^{2}$ The material for the Berlin and Kay experiment can be found on the following website: http://www.icsi.berkeley.edu/wcs/

${ }^{3}$ Unlike Androulaki et al. (2006), is demonstrated that galazio (light blue) is not a basic colour term in Modern Greek (see Serakioti \& Markopoulos, 2013: 3; Serakioti 2015), but it is included in the present questionnaire because it is used in the pair of galazoprasino (light blue-green) and prasinogalazo (green-light blue) compounds.
} 
based on the colour spectrum, and to study the semantic processes fulfilled through compounding. Furthermore, its purpose was to examine whether the alternate order of the components creates a different estimation, as well as the mechanism and process that leads to this intuition.

For this experiment (experiment 2), knowing that Greek compounds have their head on the right, we would have the intuition that the second component is the basic one (see Libben, 2006: 17). For instance, we would expect yellow-green to be a kind of green and green-yellow to be a kind of yellow. In this case, there would be a significant difference between yellowgreen and green-yellow. Bauer \& Huddleston (2002: 1658) have a similar view, arguing that colour compounds have the semantic head on the right and are therefore subordinate.

To avoid the effect of the order in which the colours are presented, a different order was used in each experiment for each volunteer, so that the elements in each experiment were alternated.

\subsection{Data statistical analysis}

For data grouping and statistical processing, tables were created, which include the speaker's serial number, gender, colour and the corresponding values for its placement on the horizontal and vertical axis of the colour spectrum. Besides, in each axis, the average was calculated, as well as the standard deviation, in order to investigate whether all values are concentrated at one point or have a large dispersion around the central value. Furthermore, the confidence interval in the vertical and horizontal position was calculated, in order to indicate the maximum probability of error (0.05). Venn diagrams were used in experiment 2 , representing the semantic relations between the two components of colour compounds.

\subsection{Sample}

The sample consisted of 30 Greek native speakers, 15 men and 15 women, aged 18-45 years, who did not have a discoloration problem (see Zeki, 1990; Rizzo et al., 1993).

\section{Research results}

\subsection{Experiment 1}

Regarding the questionnaire of the first experiment, the research results showed that the perception of basic colours in Greek (red, green, yellow, orange, blue) is located in specific areas of the colour spectrum. Regarding the central value of each colour, from tables 1 and 2 we can observe that the average value for red is $(\mathrm{x}=3.00, \mathrm{y}=5.38)$. Respectively, for orange the average value is $(\mathrm{x}=8.15, \mathrm{y}=2.70)$ with the cells $\mathrm{C} 8$ and D8 having the highest percentage of all the answers. 
Concerning green, the average is $(\mathrm{x}=16.93, \mathrm{y}=5.26)$ and $18.5 \%$ of the answers are concentrated in F17, while for yellow ( $\mathrm{x}=11.26, \mathrm{y}=1.26$ ), with a predominant cell the $\mathrm{B} 11$ at $44.4 \%$ on all answers. As for blue, the average is $(\mathrm{x}=25.22, \mathrm{y}=2.59)$ and most answers to all volunteers are in $\mathrm{C} 24$ and E25. Fewer outliers were appeared in red (29 subjects).

Table 1. Average of basic colour terms in Modern Greek

\begin{tabular}{|l|c|r|r|r|r|r|}
\hline & & kokino & prasino & kitrino & portokali & galazio \\
\hline Average & $\mathrm{x}$ & 3,00 & 16,93 & 11,26 & 8,15 & 25,22 \\
\hline & $\mathrm{y}$ & 5,38 & 5,26 & 1,26 & 2,70 & 2,59 \\
\hline Confidence & $\mathrm{x}$ & 0,44 & 0,28 & 0,20 & 0,20 & 0,64 \\
\hline Standard deviation & $\mathrm{y}$ & 0,28 & 0,45 & 0,17 & 0,29 & 0,40 \\
\hline & $\mathrm{x}$ & 1,20 & 0,73 & 0,53 & 0,53 & 1,69 \\
\hline Number of subjects & $\mathrm{y}$ & 0,78 & 1,20 & 0,45 & 0,78 & 1,05 \\
\hline
\end{tabular}

Table 2. Graphic depiction of the value of kokino (red), prasino (green), kitrino (yellow), portokali (orange), galazio (light blue) in Modern Greek.

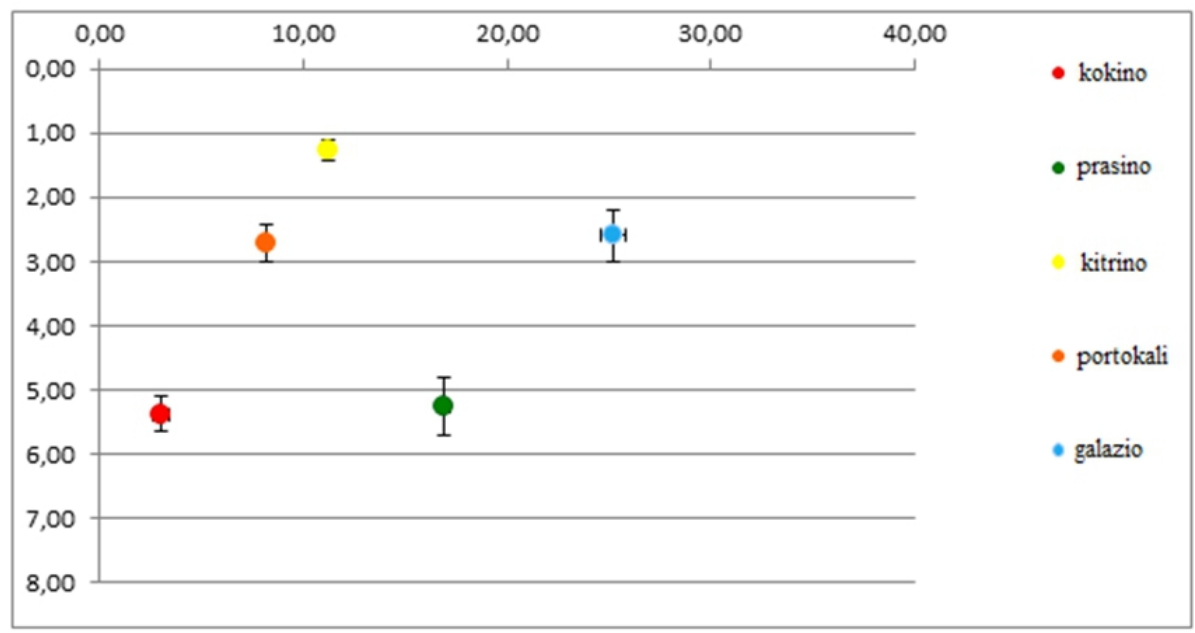

It should be noted that since the two variables $\mathrm{X}$ and $\mathrm{Y}$ are independent, with no linear correlation between them, the correlation coefficient (r) takes zero value. ${ }^{24}$

So, it is $r=\operatorname{Corr}(\mathrm{X}, \mathrm{Y})=0$.

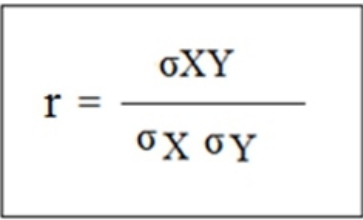

${ }^{4}$ These are continuous and not distinct variables, as long as they can take numerical values that cover the whole value range of real numbers, i.e. $-\infty<\alpha<\beta<+\infty$. 
In this case, the variables are practically irrelevant and independent $(\mathrm{r}$ $=0$ ) and it is not true that as the variable $X$ increases/decreases, so does the variable $\mathrm{Y}$ or vice versa. In the case of variables of this type, linear regression is parallel to the $\mathrm{X}$-axis $(\mathrm{b}=0)$ and, therefore, no matter how much $\mathrm{X}$ changes, $\mathrm{Y}$ is not affected.

\subsection{Experiment 2}

Regarding colour compounds, we would assume that the second constituent is the basic one, taking into consideration that in Greek the head is rightmost. For example, we would expect portokalokokino (orange-red) to be closer to red than to orange and be a kind of red, while a distinction would be made between orange-red and red-orange. Similarly, we would have the intuition that prasinokitrino (green-yellow) is a kind of yellow, while kitrinoprasino (yellow-green) is a kind of green. Ten Hacken (2000: 359) argues that colour compounds are determinative in Dutch, for example, grijsblauw (greyblue) is a type of blue (greyish blue) and blauwgrijs (bluegrey) is a kind of gray (bluish gray). Also, if the compounds with the basic colours were coordinative, as considered by Ralli (2007: 98, 2013: 158, 161), Lieber ( 2009: 47) and Manolessou \& Tsolakidis (2009: 30), then they should consist of two equal parts, without any being its basis.

According to this, for instance, portokalokokino (orange-red) is orange and red, equally and symmetrically. This view leads to the prediction that portokalokokino (orange-red) and kokinoportokali (red-orange) are the same colour, without any of the components being the basis of the other.

Nevertheless, the results of experiment 2 showed that in colour compounds the perception of the semantic structure of the compound tends to be the first component. Consequently, these compounds cannot be considered as coordinative, since there is an asymmetry between the first and second constituent and the two parts are not equal to each other. Still, they do not seem to be determinative either, as the speakers' intuition does not tend to the second constituent.

The observation that the speakers' perception tends to the first component can be established if we take into consideration the distances (d) between the constituents and the corresponding basic colours, based on the type:

$$
d=\sqrt{\left(x_{2}-x_{1}\right)^{2}+\left(y_{2}-y_{1}\right)^{2}}
$$

$\mathrm{d}=$ distance between two points

$(\mathrm{x} 1, \mathrm{y} 1)=$ Coordinates of the $1^{\text {st }}$ point

$(\mathrm{x} 2, \mathrm{y} 2)=$ Coordinates of the $2^{\text {nd }}$ point 
A Cartesian coordinate system is a pair of two vertical axes $x^{\prime} x$ and $y^{\prime} y$ that have a common origin, a point $\mathrm{O}$, and is denoted by Oxy. The point where they intersect is identified with the point (0.0) and is called the origin of the coordinate system. Table 3 depicts the distance between two points (d) on the Cartesian coordinate system.

Table 3. Distance between two points (d) on the Cartesian coordinate system.

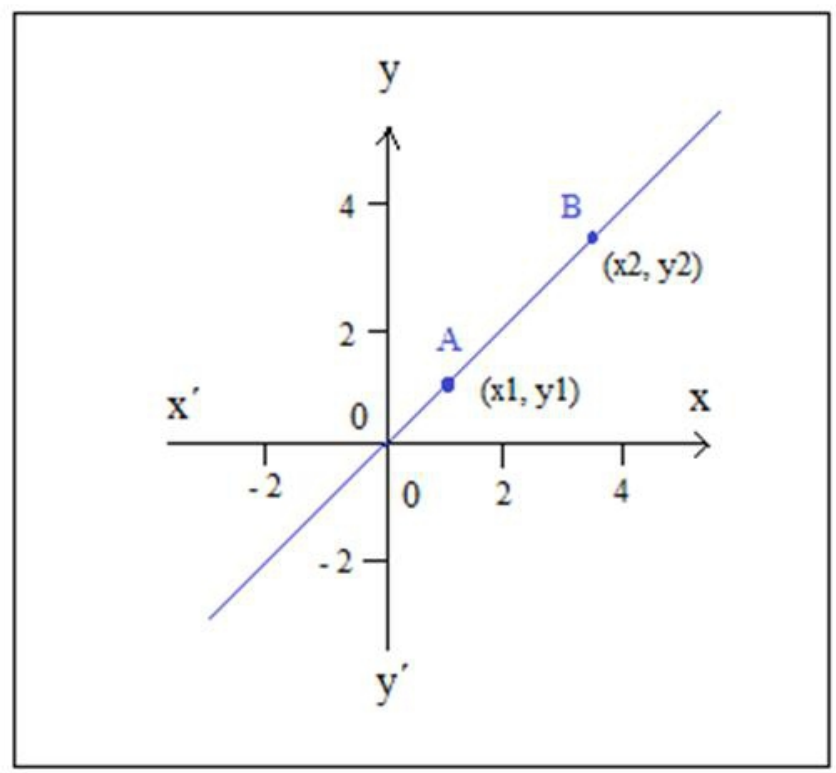

For example, if the distance between red and red-orange is smaller than that of red and orange-red, then it means that red-orange is closer to red than orange. In the same way, if the distance between orange and orange-red is smaller than that of orange and red-orange, then orange-red is closer to orange, i.e. to the first constituent.

More specifically, for the four pairs of colour compounds, the following applies to the exact distances of the compounds from the basic colours:

a) red-orange and orange-red

If $\kappa=$ red with value $(3,5,38), \pi=$ orange $(8,15,2,70), \pi \kappa=$ orange-red $(6$, $3,41)$ and $\kappa \pi=$ red-orange $(4,9,4,72)$.

Then, red-orange is closer to red, since the distance of red-orange $(\kappa \pi)$ from red $(\kappa)$ is less than the distance of orange-red $(\pi \kappa)$ from red $(\kappa)$ :

$$
|\kappa \pi-\kappa|<|\pi \kappa-\kappa|
$$




$$
2,01<3,59
$$

Similarly, orange-red is closer to orange, as the distance of orange-red from orange is less than the distance of red-orange from orange:

$$
\begin{array}{ccc}
|\pi \kappa-\pi| & < & |\kappa \pi-\pi| \\
2,26 & < & 3,83
\end{array}
$$

The distance between red and orange-red is less than that of orange-red and orange $(\mathrm{d}=0,25)$ (see Table 4$)$ :

$$
\begin{array}{cc}
|\kappa \pi-\kappa| & <\quad|\pi \kappa-\pi| \\
2,01 & 2,26
\end{array}
$$

Table 4. Graphic depiction in orange-red and red-orange.

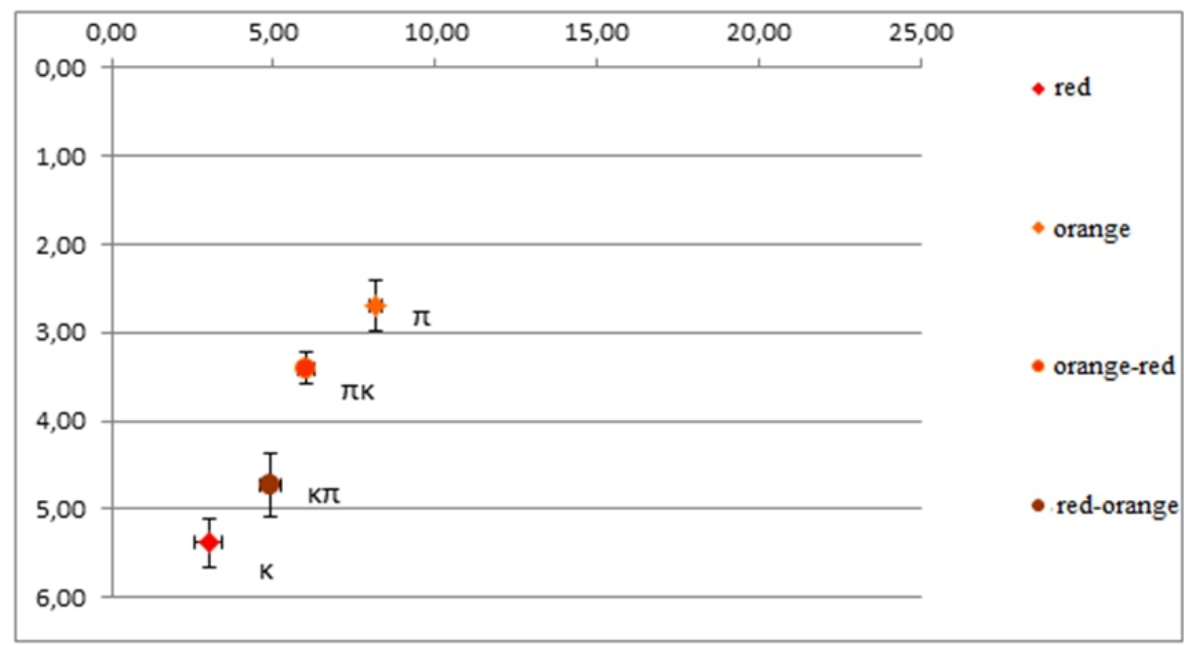

b) yellow-green and green-yellow

If $\kappa^{\prime}=$ yellow with value $(11,26,1,26), \pi^{\prime}=$ green $(16.93,5,26), \kappa^{\prime} \pi^{\prime}=$ yellowgreen $(12,5,2,38), \pi^{\prime} \kappa '=$ green-yellow $(13.55,3.76)$.

Then, yellow-green is closer to yellow, since the distance of yellow-green ( $\kappa^{\prime} \pi$ ') from yellow $\left(\kappa^{\prime}\right)$ is less than the distance of green-yellow $\left(\pi^{\prime} \kappa '\right)$ from yellow $(\kappa ')$ :

$$
\begin{array}{ccc}
\left|\kappa^{\prime} \pi^{\prime}-\kappa^{\prime}\right| & < & \left|\pi^{\prime} \kappa^{\prime}-\kappa^{\prime}\right| \\
1,67 & < & 3,39
\end{array}
$$


Similarly, green-yellow is closer to green, as the distance of green-yellow $\left(\pi^{\prime} \kappa\right.$ ') from green is less than the distance of yellow-green $\left(\kappa^{\prime} \pi^{\prime}\right)$ from green $(\pi$ '):

$$
\begin{array}{ccc}
\left|\pi^{\prime} \kappa^{\prime}-\pi^{\prime}\right| & < & \left|\kappa^{\prime} \pi^{\prime}-\pi^{\prime}\right| \\
3,70 & < & 5,28
\end{array}
$$

The distance between yellow-green from yellow is less than that of greenyellow from green $(\mathrm{d}=2,03)$ ( see Table 5):

$$
\left|\kappa^{\prime} \pi^{\prime}-\kappa^{\prime}\right|<\quad\left|\pi^{\prime} \kappa^{\prime}-\pi^{\prime}\right|
$$

Table 5. Graphic depiction in yellow-green and green-yellow.

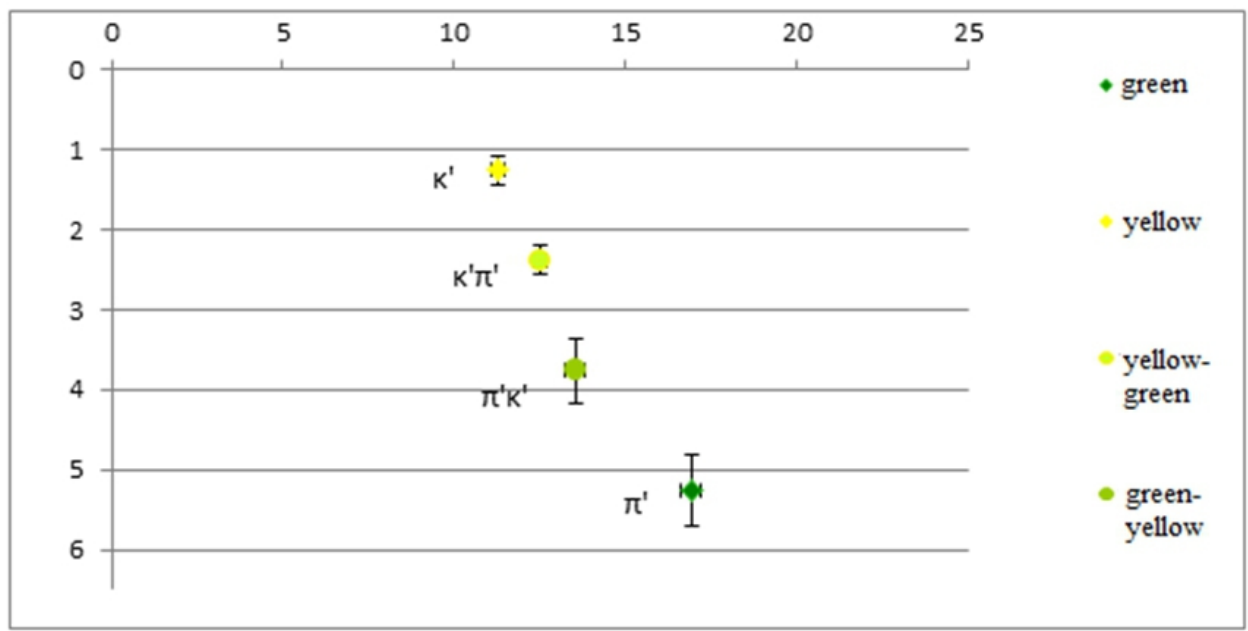

c) orange-yellow and yellow-orange

If $\pi=$ orange with value $(8,15,2,70), \kappa^{\prime}=$ yellow $(11,26,1,26), \pi \kappa^{\prime}=$ orangeyellow $(9.65,2.62)$ and $\kappa^{\prime} \pi=$ yellow-orange $(10.36,2.25)$.

Then, orange-yellow is closer to orange, since the distance of orange-yellow $\left(\pi^{\prime \prime}\right)$ from orange $(\pi)$ is less than the distance of yellow-orange $\left(\kappa^{\prime} \pi\right)$ from orange $(\pi)$ :

$$
\begin{array}{ccc}
\left|\pi \kappa^{\prime}-\pi\right| & < & \left|\kappa^{\prime} \pi-\pi\right| \\
1,50 & < & 2,26
\end{array}
$$

In the same way, yellow-orange is closer to yellow, because the distance of yellow-orange $\left(\kappa^{\prime} \pi\right)$ from yellow $\left(\kappa^{\prime}\right)$ is less than the distance of orange-yellow $\left(\pi \kappa^{\prime}\right)$ from yellow $(\kappa)$ : 


$$
\begin{array}{ccc}
\left|\kappa^{\prime} \pi-\kappa^{\prime}\right| & < & \left|\pi \kappa^{\prime}-\kappa^{\prime}\right| \\
1,34 & < & 2,11
\end{array}
$$

The distance of yellow-orange from yellow is less than that of orange-yellow from orange $(\mathrm{d}=0,16)$, while the distance of yellow-orange and orangeyellow is 0.80 (see Table 6):

$$
\begin{array}{rr}
\left|\kappa^{\prime} \pi-\kappa^{\prime}\right| & <\quad\left|\pi \kappa^{\prime}-\pi\right| \\
1,34 & 1,50
\end{array}
$$

Table 6. Graphic depiction in orange-yellow and yellow-orange.

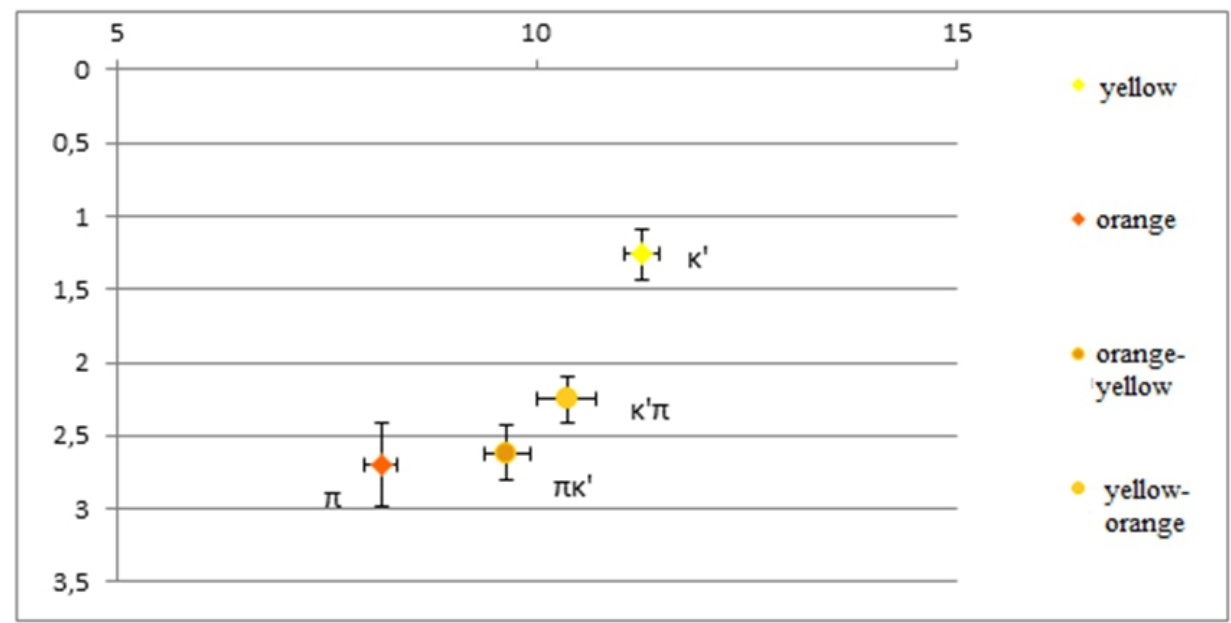

d) light blue-green and green-light blue

If $\gamma=$ light blue with value $(25,22,2,59), \pi{ }^{\prime}=$ green $(16.93,5,26), \gamma \pi^{\prime}=$ light blue-green $(21.86,3,76)$ and $\pi^{\prime} \gamma=$ green-light blue $(20.76,4.14)$.

Then, light blue-green is closer to light blue, since the distance of light bluegreen $\left(\gamma \pi^{\prime}\right)$ from light blue $(\gamma)$ is less than the distance of light blue-green $\left(\pi^{\prime} \gamma\right)$ from light blue $(\gamma)$ :

$$
\begin{array}{ccc}
\left|\gamma \pi^{\prime}-\gamma\right| & < & \left|\pi^{\prime} \gamma-\gamma\right| \\
3,56 & < & 4,72
\end{array}
$$

Similarly, green-light blue is closer to green, as the distance of green-light blue $\left(\pi^{\prime} \gamma\right)$ from green $\left(\pi^{\prime}\right)$ is less than the distance of light blue-green $\left(\gamma \pi^{\prime}\right)$ from green $\left(\pi^{\prime}\right)$ : 


$$
\begin{array}{ccc}
\left|\pi^{\prime} \gamma-\pi^{\prime}\right| & < & \left|\gamma \pi^{\prime}-\pi\right| \\
3,99 & < & 5,15
\end{array}
$$

The distance of blue-green from light blue is less than that of green-light blue from green $(\mathrm{d}=0,43)$, while the distance between light blue-green and greenlight blue is 1,16 (see Table 7):

$$
\begin{array}{cc}
\left|\gamma \pi^{\prime}-\gamma\right| \\
3,56 & \left|\pi^{\prime} \gamma-\pi^{\prime}\right| \\
3,99
\end{array}
$$

Table 7. Graphic depiction in light blue - green and green - light blue.

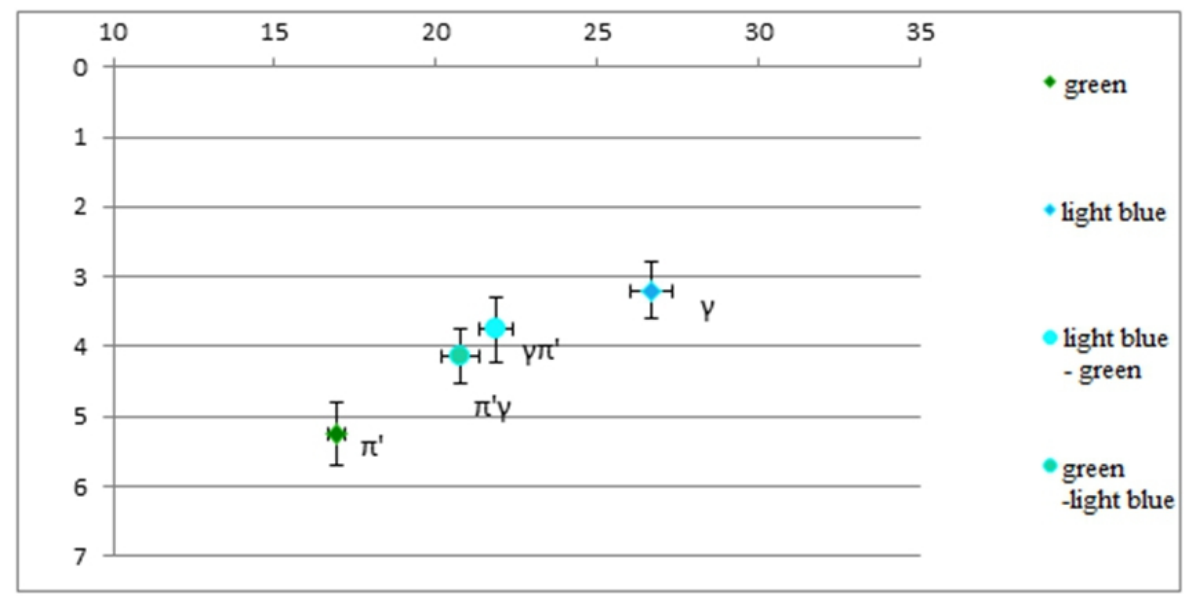

Generally, all four pairs of colour compounds are as follows:

If $\alpha \beta=$ compound colour (e.g. yellow-green), with $\alpha=$ first component (yellow),

$\beta=$ second component (green) and $\beta \alpha=$ colour compound with reversal of its components (e.g. green-yellow). Then, it applies:

$$
\begin{aligned}
& \alpha) \quad|\alpha \beta-\alpha|<|\alpha \beta-\beta| \\
& \beta) \quad|\beta \alpha-\beta|<|\beta \alpha-\alpha|
\end{aligned}
$$

Thus, in all pairs, there is a smaller distance (d) between the colour compound and the first component.

In general, observing Table 4, in kokinoportokali (red-orange) the speakers' intuition tends to be more in red than in orange, while in portokalokokino (orange-red) the appreciation tends to be more in orange than 
in red. Therefore, kokinoportokali (red-orange) is not the same as portokalokokino (orange-red). Similarly, in portokalokitrino (orange-yellow), speakers' perception tends to orange, while kitrinoportokali (yellow-orange) is closer to yellow, compared to portokalokitrino (orange-yellow) (see Table 5). Also, according to Table 6, the speakers' intuition of kitrinoprasino (yellow-green) tends to be more in the first component (yellow), in contrast to prasinokitrino (green-yellow), which is closer to green than yellow. Something alike is observed in galazoprasino (light blue-green) and prasinogalazo (green-light blue), where the reversal of components gives different results: the perception of light blue-green tends more to light blue, while for green-light blue to green (see Table 7). The summary Tables 8 \& 9 depict the average of all colour compounds in Modern Greek:

Table 8. Average of colour compounds in Modern Greek

\begin{tabular}{|c|c|c|r|r|r|r|r|r|r|}
\hline & & $\begin{array}{c}\text { orange- } \\
\text { red }\end{array}$ & \multicolumn{1}{|c|}{$\begin{array}{c}\text { red- } \\
\text { orange }\end{array}$} & $\begin{array}{c}\text { orange- } \\
\text { yellow }\end{array}$ & $\begin{array}{c}\text { yellow- } \\
\text { orange }\end{array}$ & $\begin{array}{c}\text { yellow- } \\
\text { green }\end{array}$ & $\begin{array}{c}\text { green- } \\
\text { yellow }\end{array}$ & $\begin{array}{c}\text { light } \\
\text { blue } \\
\text {-green }\end{array}$ & $\begin{array}{c}\text { green } \\
\text {-light } \\
\text { blue }\end{array}$ \\
\hline Average & $\mathrm{x}$ & 6,00 & 4,90 & 9,65 & 10,36 & 12,50 & 13,55 & 21,86 & 20,76 \\
\hline & $\mathrm{y}$ & 3,41 & 4,72 & 2,62 & 2,25 & 2,38 & 3,76 & 3,76 & 4,14 \\
\hline Confidence & $\mathrm{x}$ & 0,26 & 0,34 & 0,27 & 0,35 & 0,20 & 0,30 & 0,53 & 0,60 \\
\hline & $\mathrm{y}$ & 0,18 & 0,36 & 0,19 & 0,16 & 0,19 & 0,40 & 0,46 & 0,40 \\
\hline $\begin{array}{c}\text { Standard } \\
\text { deviation }\end{array}$ & $\mathrm{x}$ & 0,71 & 0,94 & 0,69 & 0,95 & 0,51 & 0,83 & 1,46 & 1,66 \\
\hline & $\mathrm{y}$ & 0,50 & 1,00 & 0,50 & 0,44 & 0,50 & 1,09 & 1,27 & 1,09 \\
\hline $\begin{array}{c}\text { Number of } \\
\text { subjects }\end{array}$ & & 29 & 29 & 26 & 28 & 26 & 29 & 29 & 29 \\
\hline
\end{tabular}

Table 9. Graphic depiction of colour compounds in Modern Greek

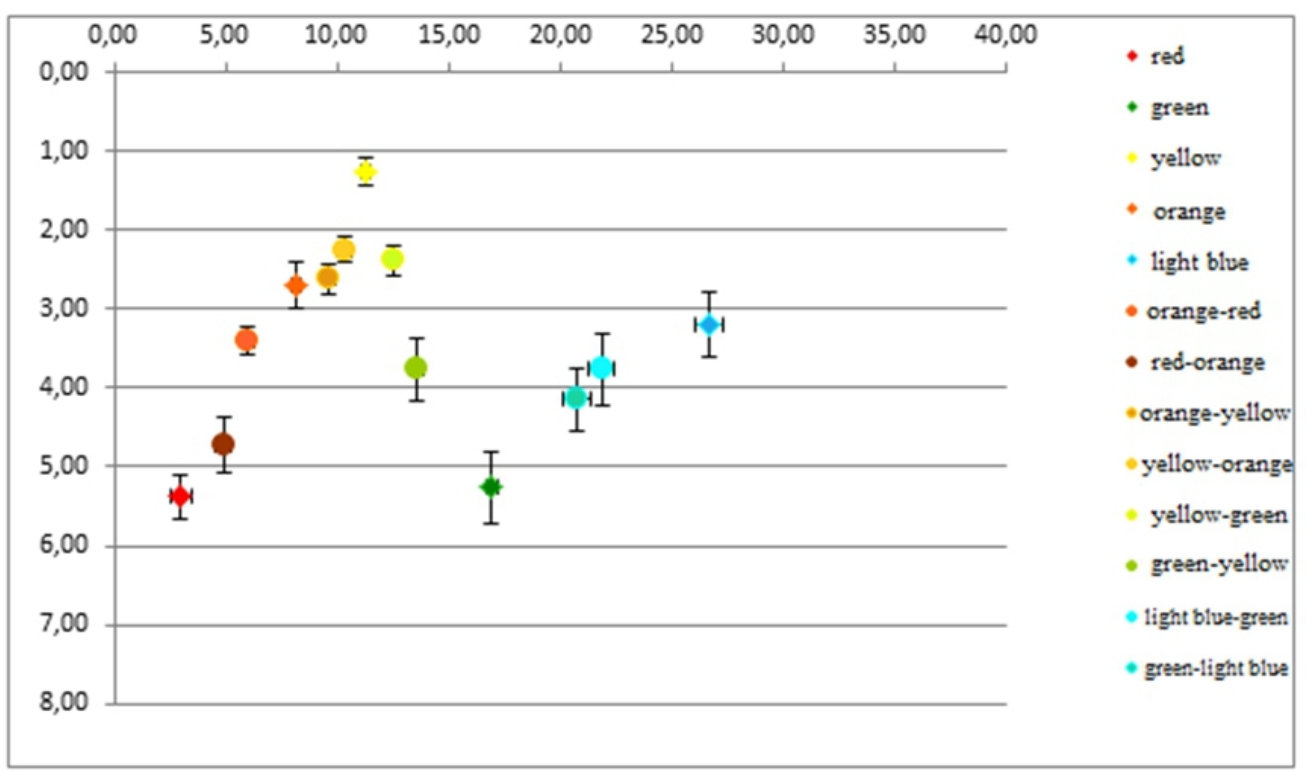


The data of the experiment seem to contradict the assumption that the experiment volunteers, based on their spontaneous intuition and the rule that applies to the determinative compounds in Greek (Right-hand Head Rule), would have the perception that the compound colour is closer to the hue of the head, e.g. that yellow-green is a kind of green and green-yellow is a kind of yellow. The main question that arises, at this point, is whether the research results are consistent with the semantic characteristics of compounding or are related to phenomena of progressive (from left-to-right) speech processing.

A cognitive view may be able to highlight the interpretation of research results. Particularly, Lakoff (1987), Langacker (1987, 2008), Bower \& Morrow (1990), Talmy (2000), Landau \& Hoffman (2005), Lewis \& Vasishth (2005), Bergen et al. (2007), point out the role of visual imagery in understanding the sentence. Langacker (2008) refers to the projection of the proposed elements, emphasizing concepts such as "directionality", "spatiotemporal displacement", "mental scanning". He also emphasizes the effect of the "linear order" on meaning, noting that the cognitive processing of the sentence starts from left-to-right (Langacker, 2008: 82). ${ }^{25}$ In addition, in the field of psychology, Dobkins \& Anderson (2002) are engaged in the progressive processing of colours based on the movement of an object, conducting a series of experiments on adults and infants.

A similar process is followed in compounding. The speaker begins the mental processing of compounds from left to right (left-to-right processing), initially trying to identify the first component and gradually moving on to the second one (Hudson \& Buijs, 1995; Libben, 1998, 2006; Isel et al., 2003: 287; Hyönä et al., 2005: 81). Taft \& Forster (1976), Sandra (1990), Kehayia et al. (1999: 376), Libben et al. (2003), Myers et al. (2004) and Kuperman et al. (2008) emphasize the superiority and dominant role of the first component, on the left-to-right compound processing by the speaker.

Based on the above, we could assume that in colour compounds the speaker starts the processing gradually from left to right, emphasizing the element that is processed first. More specifically, the first information is the first colour that the speaker hears and based on this she/he tries to orient herself/himself on the spectrum and choose the prototype version among a number of relevant cells, which are graded in terms of lightness and intensity. It is this gradation and the ability to orient and choose on the colour spectrum that distinguishes the colour compounds from the rest of the compounds. Most likely, in green-yellow, the speaker first processes green and then yellow, with the result that her/his spontaneous intuition tends towards the information that she/he receives first, that is green. Similarly, in yellow-green, yellow is

${ }^{5}$ See among others Skopeteas \& Fanselow (2009), Skopeteas (2012), Skopeteas (2016), Trotzke (2017). 
processed first and then green, gradually moving from left to right and giving emphasis to the component that appears first.

Probably, our research results could be confirmed by an additional experiment, which examines the movement of the volunteers' eyes. Furthermore, several studies have been carried out that deal with the movement of the eyes, mainly at the level of the sentence. Clifton et al. (2007) study eye movement in reading words and sentences. Henderson \& Ferreira (2004) and Trueswell \& Tanenhaus (2005) also examine the close relationship between visual and language processing.

In terms of their graphic representation, since we would expect compounds of this type to be either coordinative, as assumed in the present research literature, or determinative with the head to the right, the following representation with Venn diagrams should apply (see Table 10):

Table 10. Graphic depiction of colour compounds using Venn diagrams based on a) coordinative relationship $(\mathrm{A} \cap \mathrm{B})$ and $\mathrm{b})$ subordinate relationship $(\mathrm{A} \subseteq \mathrm{B})$.

a)

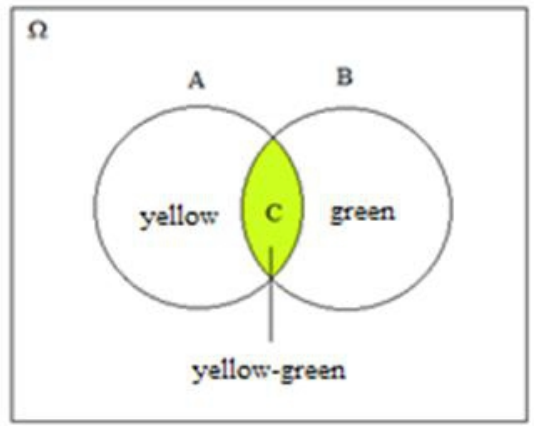

b)

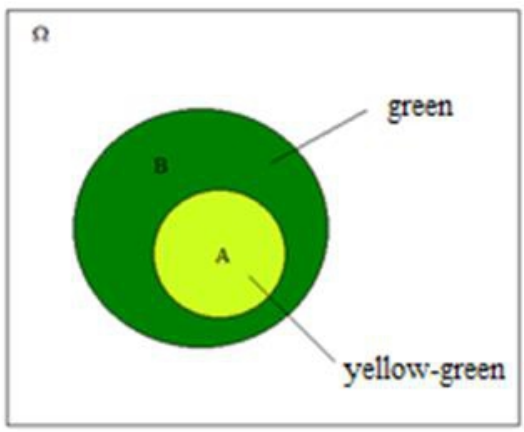

Both in the case of yellow-green and in that of green-yellow, based on the Right-hand Head Rule, we would expect that the whole compound would be subordinate of the second constituent $(\mathrm{A}=$ \{compound $\}, \mathrm{B}=\{$ second component $\}(\mathrm{A} \subseteq \mathrm{B})$. Nevertheless, the data of the experiment showed that the speakers' intuition tends to be the first component and that yellow-green is a kind of yellow, while green-yellow is a kind of green. Graphically, the data could be represented by Venn diagrams, allowing a clear representation of the semantic relationships of the whole compound and its members. Specifically, it is true that: $\mathrm{A}=\{$ yellow-green $\}, \mathrm{B}=\{$ yellow $\}$ and $\mathrm{A}\{$ green-yellow $\}, \mathrm{B}=$ \{green\}, respectively, and $\mathrm{A} \subseteq \mathrm{B}$ (Table 11). 
Table 11. Venn diagrams depicted the dominant role of the first constituent in colour compounds in Modern Greek

a)

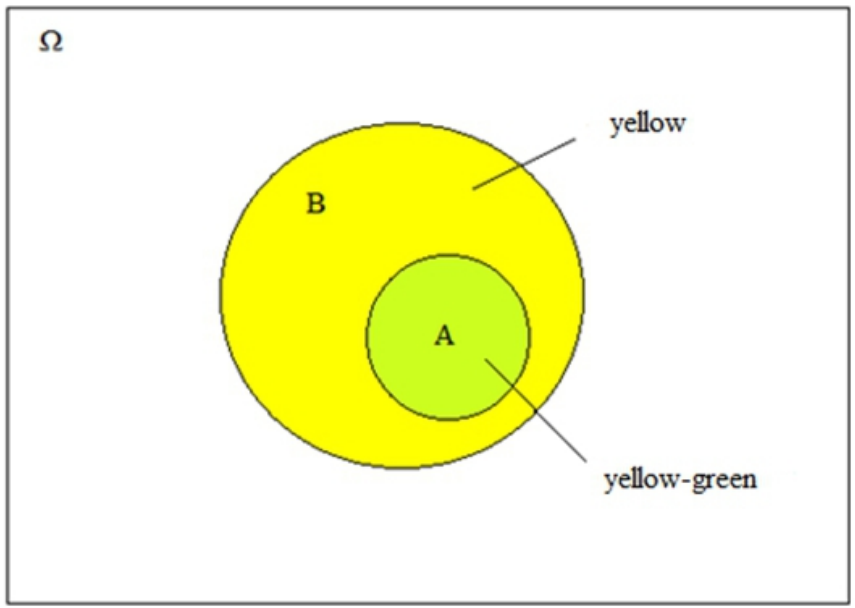

b)

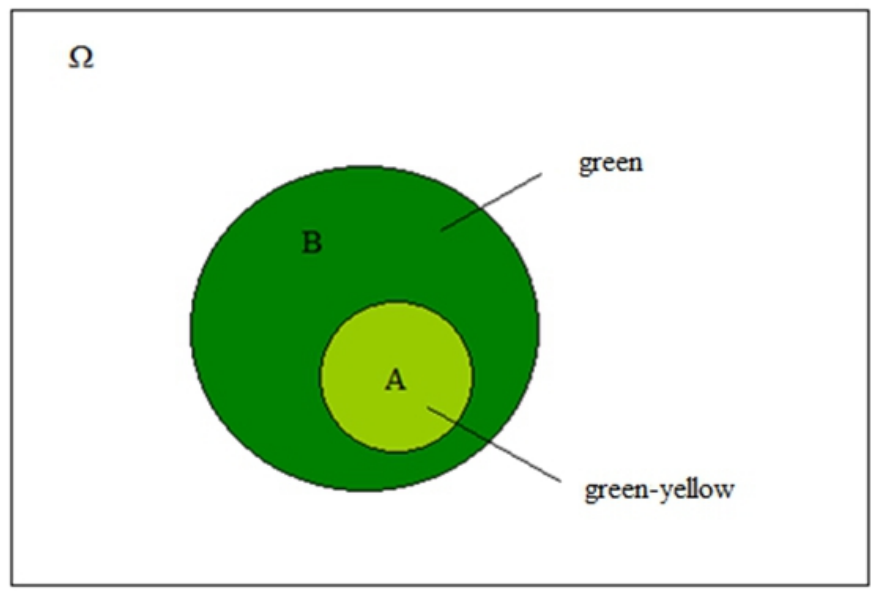

In an attempt to formulate the semantic relations of components in colour compounds it would be true that $\mathrm{A}=\{$ compound $\}, \mathrm{B}=\{$ kind of first component $\}$, in contrast to our basic assumption that $\mathrm{A}=\{$ compound $\}, \mathrm{B}=$ \{kind of second component $\}$ (see Table 12). 
Table 12. A general model in colour compound depiction using Venn diagrams

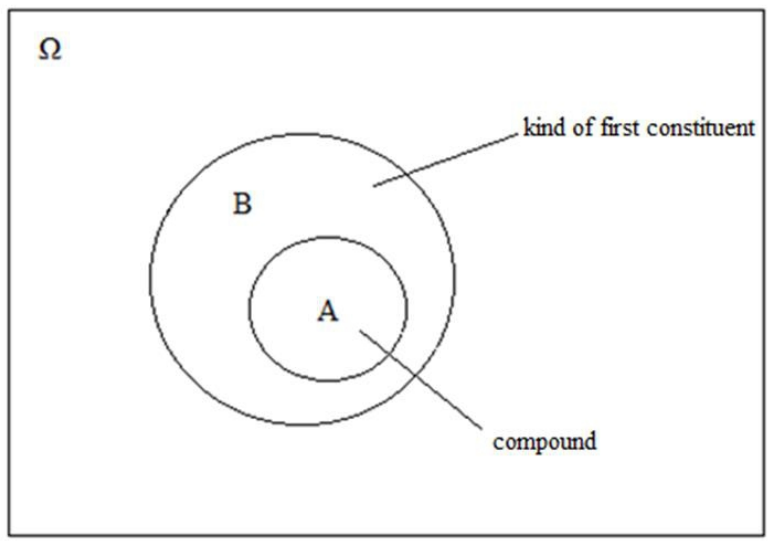

\section{Conclusion}

Through the research experiments, the semantic relations between the two components in colour compounds in Modern Greek are clear, as well as the influence that their structure exerts on the interpretation. In general, we would expect the second component to be the basic one and Right-hand Head rule to apply since in Greek the compounds have the head to the right of the structure. However, from the data of the experiments, this hypothesis is refuted, as the volunteers' intuition tends to the first and not to the second member.

Regarding the experiment 1 of the research, which is a baseline for the next experiment, the results showed that the Greek native speakers' perception of the basic colours is in specific areas of the spectrum, confirming the experiment of Berlin \& Kay (1969) on the existence of universality of colour terms. As for the experiment 2, in the research literature, the colour compounds are considered as coordinative, but we could expect that the volunteers, based on their spontaneous perception and the universal property of the Greek compounds having the head to the right, would have the intuition that the colour compound is closer to the hue of its head. Experimental research data contradicts both of these approaches. In contrast, the volunteers' perception tends more to the first constituent, e.g. in kitrinoprasino (yellowgreen) the speakers' perception tends more to yellow than to green, while in prasinokitrino (green-yellow) the intuition tends more to green than to yellow.

The research data are consistent with experiments in the field of psycholinguistics, in which the first component appears to be the most basic (see Taft \& Forster, 1976; Sandra, 1990; Kehayia et al., 1999: 376; Libben et al., 2003; Myers et al., 2004; Kuperman et al., 2008). For Modern Greek, the only study by Manouilidou et al. (2012) underlines the contribution of both constituents to coordinative compounds of Modern Greek, without the existence of asymmetry between the components, which contradicts the basic 
findings of the present research. The emphasis on the first component may be related to the progressive (from left-to-right) speech processing.

Venn diagrams and specifically the use of subsets $(\mathrm{A} \subseteq \mathrm{B})$ provide a clear representation of the semantic relations between the two components in colour compounds in Modern Greek. For example, for yellow-green we would expect either this compound to be the intersection $(A \cap B)$ of $A, B(A=$ \{green $\}, B=\{$ yellow $\})$, or $A$ to be a subset $(A \subseteq B)$ of $B(A=\{$ yellow-green $\}$, $\mathrm{B}=$ \{green. $)$, assuming that $\mathrm{A}=\{$ compound $\}, \mathrm{B}=\{$ kind of the second constituent $\}$ so $(\mathrm{A} \subseteq \mathrm{B})$. On the contrary, since the experiment data contradict the Right-hand Head Rule, it is true that if $\mathrm{A}=\{$ yellow-green $\}, \mathrm{B}=$ \{yellow $\}$ and $\mathrm{A}\{$ green-yellow $\}, \mathrm{B}=$ \{green $\}$, respectively, then $\mathrm{A} \subseteq \mathrm{B}$ so that yellowgreen is a kind of yellow and green-yellow is a kind of green.

\section{References:}

1. Androulaki, A., Gômez-Pestaña, N., Mitsakis, C., Lillo Jover, J., Coventry, K., \& Davies, I. (2006). Basic colour terms in Modern Greek: Twelve terms including two blues. Journal of Greek Linguistics 7 (1), 3-47.

2. Arcodia, G. F., Grandi, N. \& Wälchli, B. (2010). Coordination in compounding. In S. Scalise \& I. Vogel (eds.), Cross-Disciplinary Issues in Compounding. Amsterdam/Philadelphia: Benjamins, 177197.

3. Bauer, L. \& Huddleston, R. (2002). Lexical word-formation. In R. Huddleston \& G. Pullum (eds.), The Cambridge Grammar of the English Language. Cambridge: Cambridge University Press, 16211721.

4. Bauer, L. (2008). Dvandva. Word Structure 1, 1-20.

5. Bauer, L. (2017). Compounds and compounding. Cambridge: Cambridge University Press.

6. Bell, M. J. \& Schäfer, M. (2016). Modelling semantic transparency. Morphology 26(2), 157-199.

7. Bergen, B. K., Lindsay, S., Matlock, T. \& Narayanan, S. (2007). Spatial and linguistic aspects of visual imagery in sentence comprehension. Cognitive Science 31, 733-764.

8. Berlin, B. \& Kay, P. (1969). Basic Color Terms: Their Universality and Evolution. Berkeley: University of California Press.

9. Booij, G. (2007). The Grammar of Words: An Introduction to Linguistic Morphology. Second edition. Oxford: Oxford University Press.

10. Bourque, S.Y. (2014). Toward a typology of semantic transparency: The case of French compounds. Canada: University of Toronto, PhD thesis. 
11. Bower, G. H. \& Morrow, D. G. (1990). Mental models in narrative comprehension. Science 247, 44-48.

12. Clifton, C., Staub, A. \& Rayner, K. (2007). Eye movements in reading words and sentences. In R. V. Gompel, M. Fisher, W. Murray \& R. L. Hill (eds), Eye Movement Research: A Window on Mind and Brain. Oxford: Elsevier, 341-372.

13. Di Sciullo, A.-M., Williams, E. (1987). On the definition of word. Cambridge, MA: MIT Press.

14. Dobkins, K. R. \& Anderson, C. M. (2002). Color-based motion processing is stronger in infants than in adults. Psychological Science 13, 75-79.

15. Fabb, N. (2001). Compounding. In A. Spencer \& A. M. Zwicky (eds), The Handbook of Morphology. Oxford: Blackwell, 66-83.

16. Frisson, S., Niswander-Klement, E., \& Pollatsek, A. (2008). The role of semantic transparency in the processing of English compound words. British Journal of Psychology, 99(1), 87-107.

17. Gagné, C. L., \& Spalding, T. L. (2015). Semantics, concepts, and meta-cognition: Attributing properties and meanings to complex concepts. In L. Bauer, L. Körtvélyessy, \& P. Stekauer (eds.) Semantics of Complex Words. New York: Springer, 9-25.

18. Henderson, J. M. \& Ferreira, F. (2004). The Interface of Language, Vision, and Action: Eye Movements and the Visual World. New York: Psychology Press.

19. Hertzum, M. \& Frøkjær, E. (1996). Browsing and querying in online documentation: A study of user interfaces and the interaction process. ACM Transactions on Computer-Human Interaction 3(2), 131-161.

20. Hudson, P. \& Buijs, D. (1995). Left-to-right processing of derivational morphology. In L. Feldman (ed.), Morphological Aspects of Language Processing. Hillsdale, NJ: Erlbaum, 383-396.

21. Hyönä, J., Pollatsek, A. \& Bertram, R. (2005). Identifying compound words in reading: An overview and a model. In G. Underwoord (ed.), Cognitive Processes in Eye Guidance. Oxford: Oxford University Press, 79-103.

22. Isel, F., Gunter, T. C., \& Friederici, A. D. (2003). Prosody-assisted head-driven access to spoken German compounds. Journal of Experimental Psychology: Learning, Memory, and Cognition, 29(2), 277-288.

23. Jackendoff, R. (2016). English noun-noun compounds in conceptual semantics. In ten Hacken, Pius (ed.), The semantics of compounding. Cambridge: Cambridge University Press, 15-37. 
24. Jarema, G., Busson, C., Nikolova, R., Tsapkini, K., \& Libben, G. (1999). Processing compounds: A cross-linguistic study. Brain and Language, 68, 362-369.

25. Juhasz, B. J. (2007). The influence of semantic transparency on eye movements during English compound word recognition. In R. P. G. van Gompel, M. H. Fischer, W. S. Murray \& R. L. Hill (eds.), Eye movements: A window on mind and brain, 373-389.

26. Kehayia, E., Jarema, G., Tsapkini, K., Perlak, D., Ralli, A. \& Kadzielawa, D. (1999). The role of morphological structure in the processing of compounds: The interface between linguistics and psycholinguistics. Brain and Language 68 (1-2), 370-377.

27. Kuperman, V., Bertram, R. \& Baayen, R. H. (2008). Morphological dynamics in compound processing. Language and Cognitive Processes 23, 1089-1132.

28. Lakoff, G. (1987). Women, Fire, and Dangerous Things: What Categories Reveal about the Mind. Chicago: University of Chicago Press.

29. Landau, B. \& Hoffman, J. E. (2005). Parallels between spatial cognition and spatial language: Evidence from Williams syndrome. Journal of Memory and Language 53 (2), 163-185.

30. Langacker, R. W. (1987). Foundations of Cognitive Grammar: Theoretical Prerequisites. Stanford: Stanford University Press.

31. Langacker, R. W. (2008). Cognitive Grammar: A Basic Introduction. Oxford: Oxford University Press.

32. Lewis, R. L. \& Vasishth, S. ( 2005). An activation-based model of sentence processing as skilled memory retrieval. Cognitive Science 29, 375-419.

33. Libben, G. (1998). Semantic transparency in the processing of compounds: Consequences for representation, processing, and impairment. Brain and Language 61, 30-44.

34. Libben, G. (2006). Why study compound processing: An overview of the issues. In G. Libben \& G. Jarema (eds), The Representation and Processing of Compound Words. Oxford/New York: Oxford University Press, 1-22.

35. Libben, G., Gibson, M., Yoon B. Y. \& Dominiek, S. (2003). Compound fracture: The role of semantic transparency and morphological headedness. Brain and Language 84, 26-43.

36. Lieber, R. (2009). Introducing Morphology. Cambridge: Cambridge University Press.

37. Lieber, R. (2016). Compounding in the lexical semantic framework. In P. ten Hacken (ed.), The semantics of compounding. Cambridge: Cambridge University Press, 38-53. 
38. Manolessou, I. \& Tsolakidis, S. (2009). Greek coordinated compounds: Synchrony and diachrony. Patras Working Papers in Linguistics 1, 23-39.

39. Manouilidou, C., Ralli, A. \& Kordouli, K. (2012). Coordinative compounds in Greek: Lexical access and representation. Lingue $e$ Linguaggio 2012 (2), 235-250.

40. Marelli, M. \& Luzzati, C. (2012). Frequency effects in the processing of Italian nominal compounds: Modulation of headedness and semantic transparency. Journal of Memory and Language 66, 644664.

41. Myers, J., Derwing, B., \& Libben, G. (2004). The effect of priming direction on reading Chinese compounds. Mental Lexicon Working Papers, 1, 69-86.

42. Nakatsu, R. (2010). Diagrammatic reasoning in AI. Hoboken, NJ: John Wiley \& Sons.

43. Pollatsek, A. \& Hyönä, J. (2005). The role of semantic transparency in the processing of Finnish compound words. Language and Cognitive Processes 20, 261-290.

44. Ralli, A. (2007). Compounding: A cross-linguistic morphological approach [in Greek]. Athens: Patakis.

45. Ralli, A. (2009). Modern Greek V V dvandva compounds: A linguistic innovation in the history of the Indo-European languages. Word Structure 2 (1), 49-68.

46. Ralli, A. (2013). Compounding in Modern Greek. Dordrecht: Springer.

47. Rizzo, M., Smith, V., Pokorny, J. \& Damasio, A. R. ( 1993). Color perception profiles in central achromatopsia. Neurology 43 (5), 995-1001.

48. Sandra, D. (1990). On the representation and processing of compound words:

49. Automatic access to constituent morphemes does not occur. Quarterly Journal of Experimental Psychology: Human Experimental Psychology, 42, 529-567.

50. Sato Y. \& Mineshima K. (2015). How diagrams can support syllogistic reasoning: an experimental study. Journal of Logic, Language and Information, 24 (4), 409-455.

51. Scalise, S. \& Fábregas, A. (2010). The head in compounding. In S. Scalise \& I. Vogel (eds), Cross-Disciplinary Issues in Compounding. Amsterdam/Philadelphia: John Benjamins, 109-126.

52. Selkirk, E. (1982). The Syntax of Words. Cambridge, MA: MIT Press.

53. Serakioti, D. \& Markopoulos, G. (2013). An empirical approach of the basic colour terms in Greek: The effect of compounding [in Greek]. Glossologia 21, 1-18. 
54. Serakioti, D. (2015). An experimental approach to the basic colour terms in Modern

55. Greek: The case of blŭ, yalбzjo, yalany. Research Results 3 (5), 1826.

56. Serakioti, D. (2019). The semantic impact of the derivation on the interpretation: Empirical data from colour derivatives of Modern Greek [in Greek]. 13 ${ }^{\text {th }}$ International Conference on Greek Linguistics. London: University of Westminster, 369-377.

57. Skopeteas, S. \& Fanselow, G. (2009). Effects of givenness and constraints on free word order. In M. Zimmerman \& C. Féry (eds), Information structure: Theoretical, typological, and experimental perspectives. Oxford: Oxford University Press, 307-331.

58. Skopeteas S. (2012). The empirical investigation of information structure. In: Krifka M, Musan R. (eds), The expression of information structure. Berlin: Mouton De Gruyter, 216-246.

59. Skopeteas, S. (2016). Information Structure in Modern Greek. In Féry C., Ishihara S. (eds), Handbook of Information Structure. Oxford: Oxford University Press.

60. Taft, M., \& Forster, K. I. (1976). Lexical storage and retrieval of polymorphemic and polysyllabic words. Journal of Verbal Learning \& Verbal Behavior 15 (6), 607-620

61. Talmy, L. (2000). Toward a Cognitive Semantics. Cambridge, MA: MIT Press.

62. Ten Hacken, P. ( 2000). Derivation and compounding. In G. Booij, C. Lehmann, J. Mugdan \& S. Skopeteas (eds.), Morphologie/Morphology. Ein internationales Handbuch zur Flexion und Wortbildung/An International Handbook on Inflection and Word Formation. Vol. 1. Berlin: de Gruyter, 349-360.

63. Trotzke, A. (2017). The Grammar of Emphasis: From Information Structure to the Expressive Dimension. Berlin \& New York: Mouton de Gruyter.

64. Trueswell, J. C. \& Tanenhaus, M. K. (eds) (2005). Processing Worldsituated Language: Bridging the Language-as-action and Languageas-product Traditions. Cambridge, MA: MIT Press.

65. Wälchli, B. (2005). Co-compounds and Natural Coordination. Oxford: Oxford University Press.

66. Williams, E. (1981). Argument structure and morphology. The Linguistic Review 1, 81-114.

67. Zeki, S. (1990). A century of cerebral achromatopsia. Brain 113, 1721 1777. 